\title{
Suitability of temperature, hydraulic heads, and acesulfame to quantify wastewater-related fluxes in the hyporheic and riparian zone
}

\author{
Irina Engelhardt, ${ }^{1,2}$ Henning Prommer, ${ }^{3,4,5}$ Catherine Moore, ${ }^{3}$ Manoj Schulz, ${ }^{6}$ \\ Christoph Schüth, ${ }^{1}$ and Thomas A. Ternes ${ }^{6}$ \\ Received 30 June 2012; revised 13 November 2012; accepted 21 November 2012.
}

[1] Groundwater and surface water are in many cases closely linked components of the water cycle with respect to both quantity and quality. Bank filtrates may eventually be impacted by the infiltration of wastewater-derived micropollutants from surface waters. Artificial sweeteners such as acesulfame have recently been reported as a novel class of potentially valuable tracers to study the fate of wastewater-derived substances in groundwater and, in particular, to determine the (bio)degradability of micropollutants. In this paper, a model-based analysis of a field experiment within the hyporheic and riparian zone of a highly polluted German stream was performed to assess the physical and chemical behavior of the artificial sweetener acesulfame. In the first part of this study, a reliable flow and transport model was established by jointly using hydraulic heads, temperatures, and acesulfame concentrations as inverse model calibration constraints. The analysis confirmed the conservative behavior of acesulfame and, therefore, its usability as an indicator of sewage flux provenance. However, a comparison of the appropriateness of hydraulic head, temperature, and acesulfame concentrations revealed that the characterization of the surface water-groundwater flux data indicated diurnal temperature fluctuations are the best indicator in terms of characterizing the flow and transport behavior in the groundwater system.

Citation: Engelhardt, I., H. Prommer, C. Moore, M. Schulz, C. Schüth, and T. Ternes (2013), Suitability of temperature, hydraulic heads, and acesulfame to quantify wastewater-related fluxes in the hyporheic and riparian zone, Water Resour. Res., 49, doi:10.1029/ 2012WR012604.

\section{Introduction}

[2] Groundwater and surface water are in many cases closely linked components of the water cycle with respect to both quantity and quality [Winter et al., 1998]. With the steadily growing demand of groundwater and increasing uncertainty in freshwater supplies [Christensen et al., 2007], there is rising awareness that both components need to be managed as a single resource. In many countries, this has resulted in new legal frameworks aimed at better preserving groundwater systems that are hydraulically connected with surface water bodies such as rivers, drains, estuaries, and lakes [Anibas et al., 2009]. In particular, in

\footnotetext{
${ }^{1}$ Institute of Applied Geosciences, TU Darmstadt, Darmstadt, Germany. ${ }^{2}$ Agrosphere (IBG3), Institute of Bio- and Geosciences, Forschungszentrum Jülich, Jülich, Germany.

${ }^{3}$ CSIRO Land and Water, Wembley, Western Australia, Australia.

${ }^{4}$ School of Earth and Environment, University of Western Australia, Perth, Western Australia, Australia.

${ }^{5}$ National Centre for Groundwater Research and Training, Flinders University, Adelaide, South Australia, Australia.

${ }^{6}$ Federal Institute of Hydrology (BfG), Koblenz, Germany.

Corresponding author: H. Prommer, CSIRO Land and Water, Pvt. Bag No. 5, Wembley, WA 6913, Australia. (henning.prommer@csiro.au)

highly industrialized countries, these surface waters frequently contain micropollutants such as pharmaceuticals or ingredients of personal care products that predominantly originate from the discharge of sewage treatment plants [e.g., Ternes, 1998; Reddersen et al., 2002] into the rivers and drains.

[3] The area of saturated sediments beneath the streambed and into the stream banks with at least $10 \%$ stream water and less than $90 \%$ subsurface water is commonly defined as the hyporheic zone [Triska et al., 1989]. Hyporheic exchange results from pressure gradients over the stream channel boundary, which occur over a wide range of scales of topography including meanders, pool-riffle sequences, bars, and bed forms [Stonedahl et al., 2010]. The areas that surround the stream in the watershed are the riparian zones [Gregory et al., 1991] and thus form an ecotone between terrestrial and aquatic ecosystems in which deep and shallow groundwater could converge [Martínez-Santos et al., 2012]. Research over the past two decades has established that both, the hyporheic and riparian zone, have a great impact for stream ecosystem function and biogeochemistry, because hyporheic and riparian exchanges enhance the mass transfer of dissolved solutes and particulates among the stream, the streambed, and the groundwater [Puckett and Hughes, 2005].

[4] Under permanently and intermittent infiltrating conditions sewage-water-related micropollutants can enter the groundwater system and eventually threaten receptors such 
as drinking water wells [Heberer, 2002]. A reliable quantification of the micropollutant mass fluxes and whether there is a true risk to receptors are generally not trivial. Although many earlier studies relied on hydraulic head data to study the hydraulic processes during groundwater/ surface water interaction, there is now increasing evidence that such data alone are insufficient for a robust characterization of these complex exchange patterns [Keery et al., 2007] and, in particular, to quantify pollutant mass fluxes. Temperature has therefore emerged as an important and cost-effective environmental tracer to support the identification of infiltration from rivers to groundwater systems and to constrain model simulations of this process [e.g., Anderson, 2005; Stonestrom and Constanz, 2003; Engelhardt et al., 2011]. Where surface water temperatures vary sufficiently, e.g., diurnally and/or seasonally, tracking the temperature transport from surface water bodies into aquifers allows the estimation of infiltration velocities [Tangiguchi, 1994; Conant, 2004]. Due to the heat exchange between groundwater and the aquifer matrix, temperature does not behave like a conservative tracer. Instead the propagation of temperature signals is retarded by factors ranging between 2 and 4 [e.g., Brookfield et al., 2009], compared to water fluxes, depending on the porosity and the thermal properties of aquifers. For some large-scale field applications (e.g., deep well injections), it was suggested that the thermal retardation factor may even increase up to 5.3 [e.g., Therrien et al., 2010; Ward et al., 1984].

[5] Although temperature data can provide highly valuable constraints for quantifying water fluxes, additional tracers are needed to better isolate sewage-related mass fluxes from alternative sources. For more than 50 years, borate has served as a key indicator of anthropogenic wastewater. However, the use of perborate has significantly decreased for more than a decade and consequently is now less suitable as a sewage water indicator [Neal et al., 2010]. In addition, the rare earth element gadolinium $(\mathrm{Gd})$, which is used as a contrasting agent in clinical diagnosis since 1988 [Kümmerer and Helmers, 2000], is considered as a potentially suitable indicator for sewage in hydrological systems [Verplanck et al., 2005]. Gd complexes can reach surface water systems, because they are stable enough to pass nearly unaffected through common wastewater treatment plants (WWTPs) [Künnemeyer et al., 2009]. The stability, combined with low sorption and low geogenic background concentrations, favors the use of anthropogenic Gd complexes as a conservative indicator of urban wastewater in rivers [Verplanck et al., 2005]. However, the variability of the Gd release from WWTPs was shown to provide serious challenges for its use as a tracer within the hyporheic zone [Lewandowski et al., 2011].

[6] In this context, artificial sweeteners were recently proposed as novel conservative proxies to trace the migration of treated wastewater within groundwater bodies [Buerge et al., 2009]. Many of these artificial sweeteners that are consumed with food and beverages are not eliminated by the human body and are discharged almost unchanged from municipal sewage treatment plants into the receiving river waters [Daughton and Ternes, 1999; Heberer, 1995; Ternes, 1998]. Sulfonamide sweeteners such as acesulfame, cyclamate, and saccharin are anionic at typical $\mathrm{pH}$ values of groundwater and are therefore expected to behave as ideal conservative tracers, as they are not significantly adsorbed in the subsoil [Buerge et al., 2009; Scheurer et al., 2009]. However, evidence for the usefulness and effectiveness of artificial sweeteners as tracers is still rather incomplete and limited to reports of occurrence [e.g., Wolf et al., 2012]. The aim of our investigation was (i) to compare the usefulness of different data types such as piezometric pressure heads, continuously measured temperature profiles, and multilevel sampling of acesulfame concentrations to estimate the migration of sewage-water-related surface water fluxes into the hyporheic and riparian zone and (ii) to explore how this usefulness may be impacted by measurement location and the data density of the environmental tracers in the surface water and groundwater. The present study contributes to the current debate on the suitability of artificial sweeteners to better quantify the fate and degradability of micropollutants within the hyporheic zone where infiltration from surface waters occurs.

[7] In this study, we use a model-based analysis of a field data set collected from the hyporheic and riparian zone of a pollutant-stressed stream near Frankfurt, Germany, to assess the physical and chemical behavior of acesulfame within this zone. The first part of our study was dedicated to constructing and calibrating a reliable conservative transport model using hydraulic and temperature data as calibration constraints. Using this model, the appropriateness and uncertainties of acesulfame concentrations were investigated for an improved understanding of sewage-related mass fluxes.

\section{Study Site}

[8] The investigated stream, the Schwarzbach, is a tributary of the river Rhine. It is located in the Rhine valley near Frankfurt in the federal state Hessian in Germany. The superficial sediments within the rift structure of the Rhine valley are sand and gravel deposits of old braided river systems. The region is intensely used for both industry and agriculture while also serving as a source of freshwater supply.

\subsection{Hydrogeology}

[9] The upper aquifer in this area consists of quaternary sediments with grain sizes successively increasing from the top toward the bottom of the aquifer. The first (top) lithological unit consists of five layers, a silt layer on top, underlain by a sequence of fine sand, middle sand, and coarse sand, and, finally, a layer of fine gravel at the bottom of the aquifer. The fine gravel sequence is underlain by a silty clay layer. The layer thickness varies between $1 \mathrm{~m}$ at the top (layer 1) and increases to more than $10 \mathrm{~m}$ for layer 5 . The top layer has a low hydraulic conductivity of $4 \times 10^{-7}$ to $4 \times 10^{-5} \mathrm{~m} \mathrm{~s}^{-1}$. Beneath this silt layer, the hydraulic conductivity increases to within the fine $3 \times 10^{-4}$ and $1 \times$ $10^{-3} \mathrm{~m} \mathrm{~s}^{-1}$ for the middle sand aquifer [Engelhardt et al., 2011]. The riverbed sediments reach a hydraulic conductivity of $5 \times 10^{-5}$ and $4 \times 10^{-4} \mathrm{~m} \mathrm{~s}^{-1}$, indicating that a pronounced clogging layer of reduced permeability due to a higher silt, clay, or organic material content is absent. The groundwater system is semiconfined. Within the investigated region, groundwater generally tends to flow from East to West toward the Rhine River with a mean hydraulic gradient of 5\% and a regional mean flow velocity of $1 \mathrm{~m} \mathrm{~d}^{-1}$. Within the field site, depth to the water table ranges between 
0.9 and $1.4 \mathrm{~m}$ in zones close to the Schwarzbach and increases to $>2 \mathrm{~m}$ at the eastern border of the site, $220 \mathrm{~m}$ downstream of the Schwarzbach.

\subsection{Hydrology and Climate}

[10] Precipitation and air temperature are recorded on a daily basis at the meteorological station in Groß-Gerau, about $3 \mathrm{~km}$ from the field site. The investigated period extends from late summer to autumn: 15 August 2010 to 9 October 2010. During the field experiment, only some sporadic rain events occurred, with a maximum rainfall intensity of $30 \mathrm{~mm} \mathrm{~d}^{-1}$ at the end of August, whereas most of the days remained dry. Measured soil temperatures at $10 \mathrm{~cm}$ depth varied between $10^{\circ} \mathrm{C}$ and $23^{\circ} \mathrm{C}$ during this period.

[11] At the study site, the gradient of the Schwarzbach ranges at $0.8 \%$ with a mean discharge of $0.6 \mathrm{~m}^{3} \mathrm{~s}^{-1}$, as measured between 2008 and 2011. However, maximum short-term discharge can reach values of $3.8 \mathrm{~m}^{3} \mathrm{~s}^{-1}$ after precipitation events. Thus, the stage of the river also varies distinctively between $0.21 \mathrm{~m}$ during dry summer periods but can rise up to $1.15 \mathrm{~m}$ after intense rain periods in autumn.

\subsection{Data Collection}

[12] The investigated two-dimensional (2-D) transect is oriented perpendicular to the streambed and aligned with the direction of natural groundwater flow. The field site was equipped with 17 groundwater monitoring wells (GWM) aligned along the $253 \mathrm{~m}$ transect. All monitoring wells were equipped with polyethylene filter screens with $0.3 \mathrm{~mm}$ filter slots over the entire depth of the well. Observation wells were placed $26 \mathrm{~m}$ upgradient of the stream, directly beneath the streambed, and at various distances over $220 \mathrm{~m}$ downgradient of the stream (Figure 1). Pressure transducers (STS and Solinst) were installed within the observation wells. One further pressure transducer was placed on the riverbed to monitor the river stage.

[13] At some field sites, a more pronounced fully threedimensional (3-D) hyporheic and riparian flow behavior was documented by Schmidt et al. [2006] with heat sensors and more recently by Angermann et al. [2012] with a heat pulse technique. Their investigations documented the magnitude of hyporheic fluxes along the stream. However, at the investigated field site, the measured piezometric pressure head distribution suggests that a 2-D approach should be a justifiable approximation to capture the majority of the exchange fluxes [Engelhardt et al., 2011] between surface water and groundwater.

[14] Bundle-type multilevel PT-100 temperature sensors (TITEC, Germany) with a vertical resolution of $20 \mathrm{~cm}$ were installed for the continuous monitoring of vertical one dimensional profiles of groundwater temperatures at selected locations. One multilevel bundle measured temperature profiles up to a depth of $2.35 \mathrm{~m}$ directly below the riverbed (TML 1). A second multilevel bundle recorded temperatures at $3.4 \mathrm{~m}$ downgradient of the river (TML 2). In the Schwarzbach itself, water levels as well as water temperatures were recorded continuously.

[15] Vertical concentration profiles for acesulfame were collected along the monitoring transect. Level-accurate water sampling was undertaken with a buffle-packer device. The baffle-packer system was connected with a suction pump, inserted into the well, and then pushed down to the desired sampling depth. The stagnant well water was removed before the groundwater sample was taken. Subsequently, the buffle-packer system was pushed to the next deeper sampling depth. Samples were taken at three levels (top, middle, and bottom of the filter screen) within GWM0 (26.2 m upgradient), GWM2a (0.7 m downgradient), GWM2c (3.4 $\mathrm{m}$ downgradient), and GWM5 (7.6 $\mathrm{m}$ downgradient;

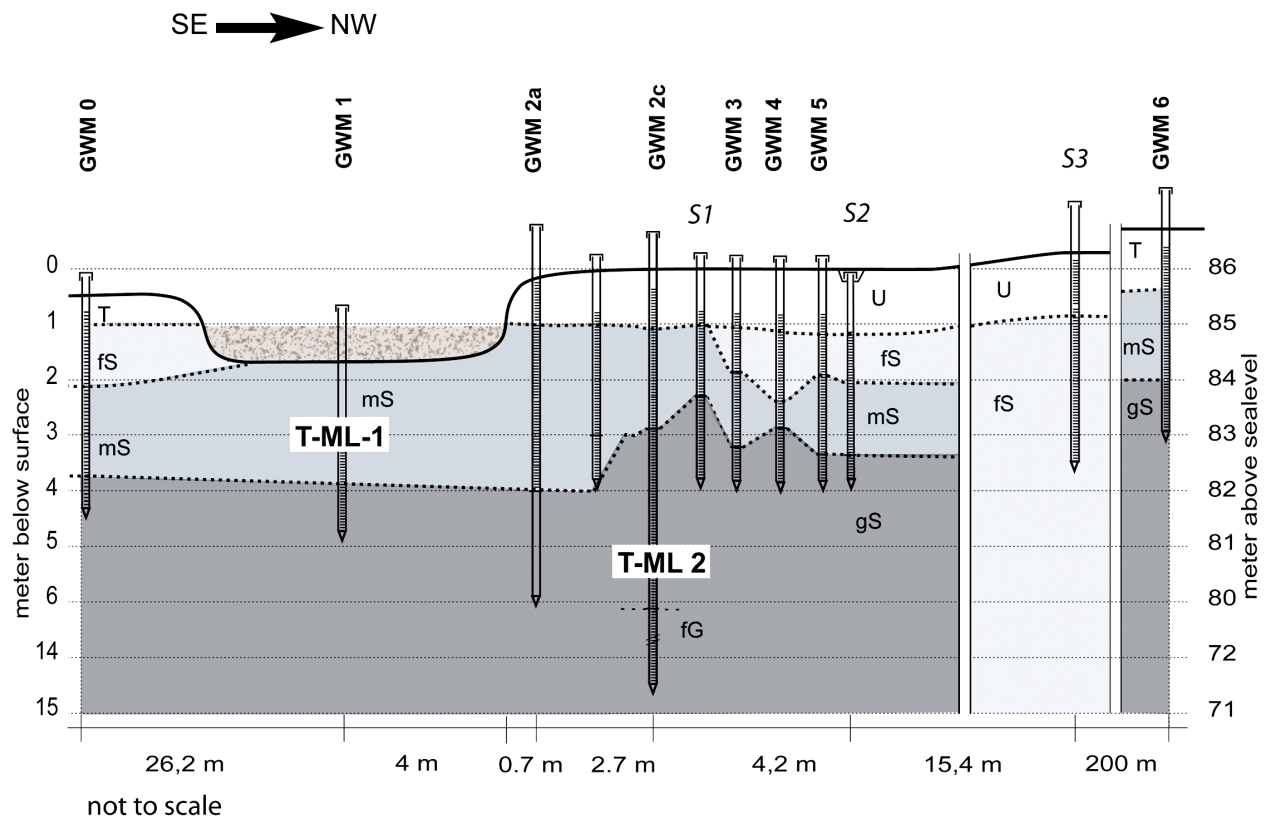

Figure 1. Multilevel monitoring network along a potential flow line. The investigated transect covers $227 \mathrm{~m}$ downgradient and $26 \mathrm{~m}$ upgradient of the river bank. U, silt; $\mathrm{T}$, clay; fS, fine sand; mS, middle sand; gS, coarse sand; fG, fine gravel. 
Figure 1). One additional water sample was collected within the middle of the stream. All water samples were preserved by acidification immediately after sampling. Acidification of the water samples to $\mathrm{pH}<2$ was used to prevent microbial activity and sorption losses that would change the dissolved acesulfame concentrations. In the laboratory, groundwater and river water samples were filtered through glass fiber filters (GF 6, Schleicher and Schuell, Dassel, Germany) and then analyzed for acesulfame (molecular formula: $\mathrm{C}_{4} \mathrm{H}_{4} \mathrm{NO}_{4} \mathrm{~S}$, molecular weight: $162.14 \mathrm{u}$ ). However, in the food and pharmaceutical production, the potassium salt of acesulfame (acesulfame-K, molecular formula: $\mathrm{C}_{8} \mathrm{H}_{8} \mathrm{KN}_{2} \mathrm{O}_{8} \mathrm{~S}_{2}$, molecular weight: $363.39 \mathrm{u}$ ) is used as an artificial sweetener, which dissociates into acesulfame in water. For the analysis of acesulfame sample, aliquots of $1 \mathrm{~mL}$ were spiked with $100 \mathrm{ng}$ of acesulfame-d4, evaporated at $45^{\circ} \mathrm{C}$ to $100 \mu \mathrm{L}$, filled up with methanol to $1 \mathrm{~mL}$, and then analyzed by high-performance liquid chromatography-tandem mass spectrometry (HPLC MS).

\section{Numerical Modeling}

\subsection{Conceptual Model Setup}

[16] The vertical cross-sectional model extends approximately $250 \mathrm{~m}$ across the sets of upgradient and downgradient monitoring wells depicted in Figure 1. The five aquifer zones were discretized by a grid of 243 rows and 31 layers with a top elevation of $86 \mathrm{~m}$ above sea level (asl) and a bottom elevation of $60 \mathrm{~m}$ asl. The selected layer thickness was $0.2 \mathrm{~m}$ in the zone of water table fluctuations and increased successively with depth. The simulated period of 55 days was discretized into stress periods of $2 \mathrm{~h}$. During this period, transient piezometric heads measured within the observation well GWM2a (0.7 $\mathrm{m}$ away from the river bank) and S3 (23 $\mathrm{m}$ away from the river bank), and multilevel temperature data collected beneath the riverbed (TML1) and $3.4 \mathrm{~m}$ away from the river bank (TML2; Figure 1) were used as calibration constraints. For the second phase of the simulation period (15 September to 9 October 2010), multilevel water samples taken at GWM2a, GWM2c, and GWM5 every second day were analyzed for the artificial sweetener acesulfame and were also used as calibration constraints. With this model setup and database, a multispecies model was developed, with joint inversion of flow, temperature, and solute transport of the artificial sweetener acesulfame.

\subsection{Modeling Tools}

[17] The standard finite-difference model MODFLOW [Harbaugh, 2005] was used for the flow simulations, whereas solute and temperature transport were simulated with the multispecies transport simulator MT3DMS [Zheng and Wang, 1999], as demonstrated and discussed in earlier studies by Thorne et al. [2006], Langevin et al. [2009], Ma et al. [2010], and Hecht-Méndez et al. [2010]. The nonlinear parameter estimator (PEST) [Doherty, 2010] was used for the automated model calibration through an inverse parameter estimation process based on the Gauss-Marquardt-Levenberg method.

\subsection{Flow Model}

[18] The zonation of the hydraulic conductivity and porosity followed the geological profile and was represented by a homogenous property distribution in the lateral direction. Values for horizontal and vertical hydraulic conductivity were estimated in the inversion process. Specific storage was assigned homogeneously over the whole model domain. The SE (southeast) inflow boundary was defined by a time series of prescribed hydraulic heads generated from the pressure heads measured at the observation well GWM0 (Figure 1). The NW boundary was defined as a general head boundary, representing the head difference that prevailed across the model domain boundary, as derived from the groundwater level measured in GWM6. For both boundaries, daily averages were used for the temporal discretization. The model bottom, which corresponds to the top of the low permeable silty clay layer, was defined as a no-flow boundary. Groundwater recharge was applied to the uppermost active model layer. Recharge rates were approximated from the measured precipitation assuming that $15 \%$ of the precipitation infiltrated into the groundwater as reported by Berthold and Hergesell [2005]. They employed a geographic-information-system-based analysis that integrated the regional hydrology (precipitation, temperature, wind, and radiation), local topography, geology, and soil types. The simulated soil water balance and recharge rates within the catchment were constrained by measured discharges. River stage variations were represented using a time-varying head boundary and assigned to the model cells representing the river bottom (time discretization $2 \mathrm{~h}$ ). Initial heads for $t=0$ were defined on the basis of the averaged head gradient that was measured between observation wells GWM0 and GWM6.

\subsection{Temperature Transport Model}

[19] Conductive-convective heat transport in a 3-D field is described by the following equation [Domenico and Schwartz, 1990; Anderson, 2005]:

$$
\frac{\partial T}{\partial t}=\frac{\lambda_{m}}{\rho_{m} c_{m}} \nabla^{2} T-\frac{\rho_{w} c_{w}}{\rho_{m} c_{m}} \nabla \cdot(T v),
$$

where $T$ is the temperature $\left({ }^{\circ} \mathrm{C}\right), t$ is the time (s), $v$ is the seepage velocity $\left(\mathrm{m} \mathrm{s}^{-1}\right), \lambda_{m}$ is the thermal conductivity of the matrix $\left(\mathrm{W} \mathrm{m}^{-1} \mathrm{~K}^{-1}\right), \rho_{w}$ is the density of water $\left(\mathrm{kg} \mathrm{m}^{-3}\right), c_{w}$ is the specific heat of water $\left(\mathrm{J} \mathrm{g}^{-1} \mathrm{~K}^{-1}\right)$, and $\rho_{m} c_{m}$ gives the effective heat capacity of the matrix $\left(\mathrm{J} \mathrm{kg}^{-1} \mathrm{~K}^{-1}\right)$, which is defined by the following equation:

$$
\rho_{m} c_{m}=n \rho_{w} c_{w}+(1-n) \rho_{S} c_{S}
$$

where $n$ is the porosity $(-), \rho_{S}$ is the density of the grains $\left(\mathrm{kg} \mathrm{m}^{-3}\right), c_{S}$ is the specific heat of the grains $\left(\mathrm{J} \mathrm{kg}^{-1} \mathrm{~K}^{-1}\right)$, $\rho_{m}$ is the density of the matrix $\left(\mathrm{kg} \mathrm{m}^{-3}\right)$, and $c_{m}$ is the specific heat of the matrix $\left(\mathrm{J} \mathrm{kg}^{-1} \mathrm{~K}^{-1}\right)$.

[20] The term $\lambda_{m} / \rho_{m} c_{m}$ in equation (1) is analogous to the hydrodynamic dispersion in the standard advectivedispersive solute transport equation [e.g., Ma et al., 2012] and includes effects of thermal diffusivity through the rockfluid matrix as well as effects of thermal dispersivity, caused by velocity variations within the pore space [Anderson, 2005]. Thermal diffusivity is much more important for heat transport than molecular diffusion for solute transport [Vandenbohede et al., 2009]. Thermal diffusion coefficients range at our study site, depending on the prevailing lithology, between $1.2 \times 10^{-4} \mathrm{~cm}^{2} \mathrm{~s}^{-1}$ (fine and middle sand) 
and $1.1 \times 10^{-3} \mathrm{~cm}^{2} \mathrm{~s}^{-1}$ (riverbed sediments), whereas the molecular diffusion coefficient for acesulfame ranges around $1.15 \times 10^{-6} \mathrm{~cm}^{2} \mathrm{~s}^{-1}$.

[21] Reported values of thermal dispersivity vary strongly between zero [Hopmans et al., 2002] and similar values obtained for solute dispersivity [Vandenbohede et al., 2009]. Following de Marsily [1986], we assumed the same values for thermal and solute dispersivity.

[22] For an initial estimate (starting value) of the saturated thermal conductivity of the matrix, $\lambda_{m}\left(\mathrm{~W} \mathrm{~m}^{-1} \mathrm{~K}^{-1}\right)$ values were derived from the Johansen [1975] model that is based on the geometric mean and postulates a simple relationship among soil structure, water content, and thermal properties of the porous medium (equation (3)):

$$
\lambda_{m}=\lambda_{s}^{1-n} \lambda_{w}^{n}
$$

where $\lambda_{w}$ is the thermal conductivity of the water (W m $\mathrm{m}^{-1} \mathrm{~K}^{-1}$ ), and $\lambda_{s}$ is the thermal conductivity of the solid $\left(\mathrm{W} \mathrm{m} \mathrm{m}^{-1} \mathrm{~K}^{-1}\right)$ that can be estimated from the quartz and silt content [Lu et al., 2007] (equation (4)):

$$
\lambda_{s}=\lambda_{q}^{q} \lambda_{u}^{u}
$$

where $\lambda_{q}$ equals the thermal conductivity of quartz grains $\left(7.7 \mathrm{~W} \mathrm{~m}^{-1} \mathrm{~K}^{-1}\right)$, the exponent $q(-)$ equals the percentage of sand and gravel within the sample, $\lambda_{u}$ equals the thermal conductivity of silt $\left(2-3 \mathrm{~W} \mathrm{~m}^{-1} \mathrm{~K}^{-1}\right)$, and the exponent $u$ $(-)$ equals the percentage of silt and clay within the sample.

[23] Initial estimates of the specific heat of the matrix $c_{m}$ and solid $c_{s}$ were also calculated using a geometric mean equation (equations (5) and (6)):

$$
c_{m}=c_{s}^{1-n} c_{w}^{n}
$$

and the specific heat of the solid $c_{s}$ is given by the quartz and silt content:

$$
c_{s}=c_{q}^{q} c_{u}^{u}
$$

where $c_{q}$ is the specific heat of quartz $\left(700 \mathrm{~J} \mathrm{~kg}^{-1} \mathrm{~K}^{-1}\right)$, and $c_{u}$ is the specific heat of silt $\left(1400 \mathrm{~J} \mathrm{~kg}^{-1} \mathrm{~K}^{-1}\right)$. Both thermal conductivity and specific heat were varied during the inverse parameter estimation process due to variations in porosity among the five different aquifer layers.

[24] For the simulation of the heat transport with MT3DMS, thermal conductivity and specific heat are converted into the thermal distribution coefficient $K_{d, t h}$, thermal diffusivity $D_{t h}$, and thermal retardation $R_{t h}$ [e.g. Shook, 2001; Ma and Zheng, 2010]. The thermal distribution coefficient and thermal retardation account for heat exchange between the solids and water. Thermal diffusivity represents heat conduction as described by Fourier's law.

[25] For simplicity, constant density, viscosity, time-invariant hydraulic conductivities, and thermal conductivities were assumed, which is a reasonable assumption for the conditions of this study. The temperature transport was simulated on the basis of the a priori computed transient flow field. Along the SE inflow boundary variable temperatures were defined on the basis of daily averaged temperature data measured at the observation well GWM0. Multilevel temperature measurements within these observation wells allowed identifying and assigning a representative initial vertical temperature gradient. At the model bottom, a constant temperature of $12^{\circ} \mathrm{C}$ prevailed (Figure 2). The recharge temperature was assigned according to the soil temperature at $10 \mathrm{~cm}$ depth that was measured daily at the meteorological station in Groß-Gerau, $3 \mathrm{~km}$ from the field site. The surface water temperature was assigned as the prescribed temperature boundary to the river cells with a temporal resolution of $2 \mathrm{~h}$.

\subsection{Solute Transport Model}

[26] The acesulfame transport was simulated with the advective-dispersive transport equation as provided by $M a$ et al. [2012].

[27] Values for the molecular diffusion coefficient of acesulfame can be derived from its liquid molecular volume [Appelo and Postma, 2005] and range around $1.15 \times$ $10^{-6} \mathrm{~cm}^{2} \mathrm{~s}^{-1}$. The molecular diffusion coefficient slightly increases with temperature; however, molecular diffusion plays a negligible role in the present study. The value of

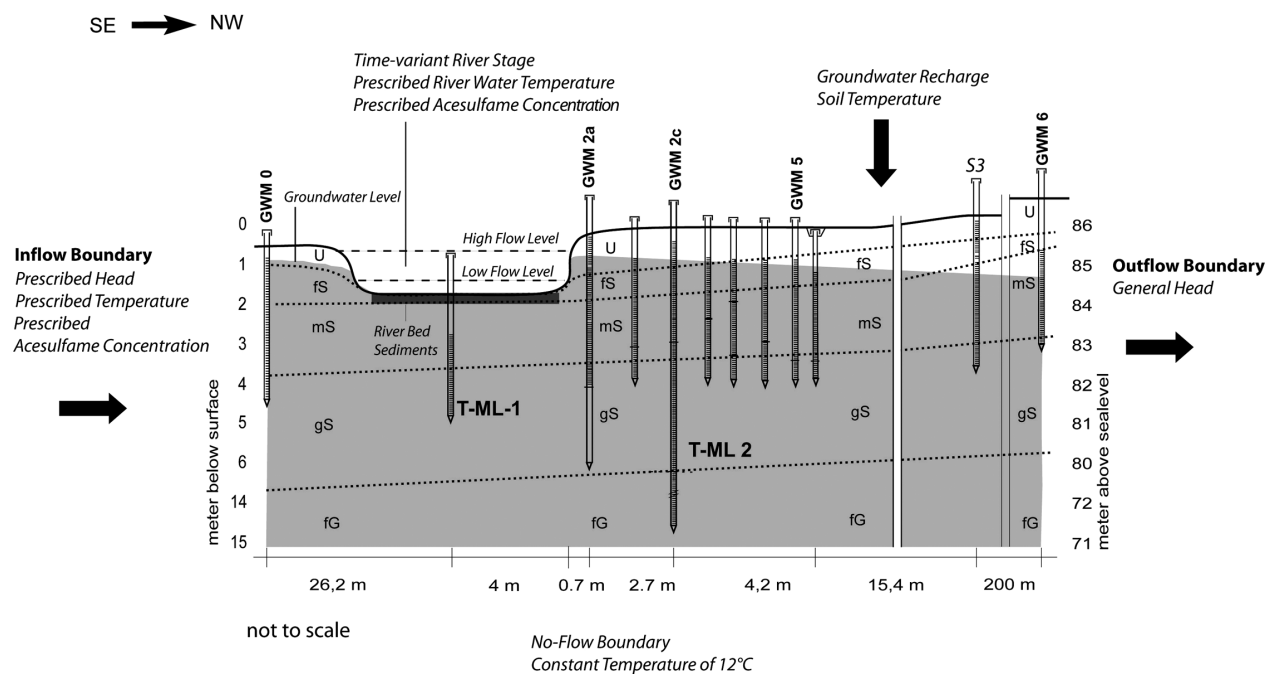

Figure 2. Conceptual model setup, boundary conditions, and simplified hydrostratigraphic zonation. 
the dispersion coefficient is therefore, as in many other cases, driven by the physical dispersion term. Both longitudinal and transverse dispersivity were estimated with the inverse model and assumed to be the same for both temperature and solute transport.

[28] The initial acesulfame concentration in the groundwater was averaged from all acesulfame data collected at GWM0 and assigned homogenously with a mean value of $5 \times 10^{-8} \mathrm{~mol} \mathrm{~L}^{-1}$ over the whole model domain. This was reasonable as the sensitivity of results to the starting value was found to be low. The same value was assigned as a constant concentration to the inflowing water at the SE (upstream) model boundary, as a background concentration of acesulfame already prevailed within the groundwater.

[29] The acesulfame concentrations of the river water were measured every second day between 15 September and 9 October 2010, with concentrations varying between $1.3 \times 10^{-7}$ and $7 \times 10^{-8} \mathrm{~mol} \mathrm{~L}^{-1}$ with an average concentration of $9.6 \times 10^{-8} \mathrm{~mol} \mathrm{~L}^{-1}$ and a detection limit of $0.2 \mathrm{nmol} \mathrm{L}^{-1}$. For the initial part of the simulation period where there were no acesulfame measurements, between 15 August and 14 September 2010, time-variant acesulfame concentrations were reconstructed for the Schwarzbach. For this, the acesulfame mass load of the river was calculated for each water sample based on the measured acesulfame concentration of the river water and the prevailing river discharge, respectively. The acesulfame mass load between 15 September and 9 October 2010 varied insignificantly between $9.5 \times 10^{-5}$ and $1.3 \times 10^{-4} \mathrm{~mol} \mathrm{~s}^{-1}$ within a mean acesulfame mass load of $1.2 \times 10^{-4} \mathrm{~mol} \mathrm{~s}^{-1}$. By assuming a constant acesulfame mass load of $1.2 \times$ $10^{-4} \mathrm{~mol} \mathrm{~s}^{-1}$ for the entire spin-up period, the acesulfame concentrations of the river were computed as a function of the measured discharge (Figure 3) with a daily discretization. This resulted in generally higher acesulfame concentrations for low-flow conditions and lower concentrations during periods of increased river discharge consistent with the observed trend during the measurement period.

\subsection{Groundwater Age Simulation}

[30] The calibrated model was used to simulate groundwater ages to illustrate the residence times of infiltrating surface water and groundwater recharge. The corresponding simulations were also carried out with MT3DMS by

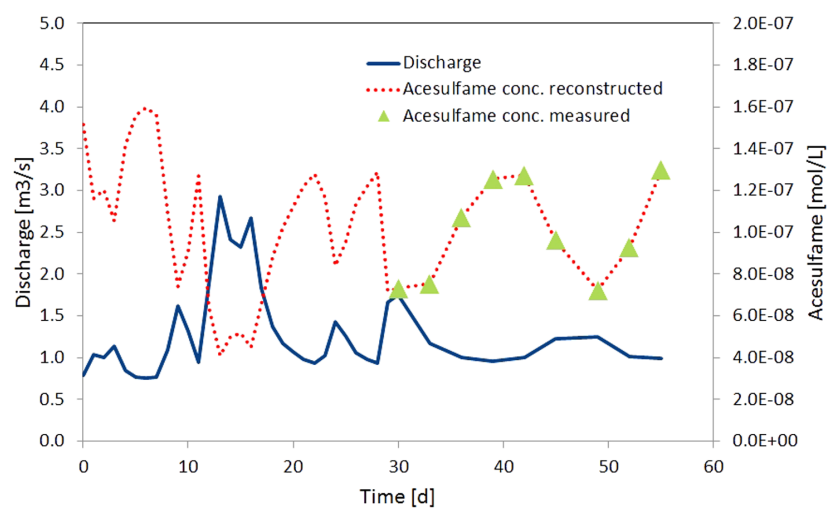

Figure 3. Measured discharge in the Schwarzbach stream, together with the measured and reconstructed acesulfame concentrations. employing a zero-order irreversible production rate as, for example, discussed in more detail by Levenspiel [2002] and Zheng [2010]. The groundwater age was simulated using the solute transport equation [Ma et al., 2012]. However, the effect of dispersive mixing of groundwater with different ages would limit maximum groundwater ages as dispersive flux occurs away from regions with higher groundwater ages and only mean groundwater ages can be obtained [e.g., Goode, 1996; Varni and Carrera, 1998]. Therefore, for simulating the groundwater age, longitudinal and transverse dispersivity were set to zero, and the particle-tracking method (methods of characteristics), which effectively limits numerical dispersion, was employed. Note that calculated groundwater ages do not directly correspond to the true groundwater age, but to the age since the start of the simulation or to the time since entering the aquifer via recharge or surface water infiltration. This allowed for the delineation of zones that have received fresh infiltration (younger age) and regions unaffected by infiltration.

\subsection{Model Calibration}

[31] The joint inversion of the flow and contaminant transport models were constrained by continuously measured piezometric pressure heads, 2-D multilevel temperature data over a period of 55 days, and acesulfame concentrations collected over a period of 25 days on every second day. Initial parameter values were based on the interpretation of pumping test (hydraulic conductivity, storage, porosity) and literature data (thermal conductivity, specific heat capacity, diffusion, thermal distribution coefficient, bulk density) and then optimized during the inversion process. PEST minimizes discrepancies between model simulated outputs and the corresponding measurements by minimizing the weighted sum of squared differences between the respective values. In the optimization procedure, the significance of the included data types (temperature, piezometric heads, acesulfame concentration) as well as measurement errors of the collected data is considered by assigning appropriate weighting factors. When optimally assigned, these weighting factors result in a sum of squares objective function equal to the number of measurements, which allows a number of ancillary analyses based on the least-squares regression theory as implemented below.

[32] PEST computes sensitivities of all observation points. Sensitivity is converted into the dimensionlessscaled sensitivity dss [Hill, 1992; Hill et al., 1998] using equation (7):

$$
\operatorname{dss}_{i j}=\left.\left(\frac{\partial y_{i}^{\prime}}{\partial b_{j}}\right)\right|_{b}\left|\mathbf{b}_{j}\right| \omega_{i i}^{1 / 2},
$$

where $\partial y_{i}^{\prime} / \partial b_{j}$ is the sensitivity $(-)$ calculated by PEST, b is a vector that contains the parameter value, $\omega$ is the observation weight derived from the observation error, $i$ is the observation points, and $j$ is the adjusted model parameter.

[33] The results provide a measure of how much a simulated value (piezometric head, temperature, acesulfame concentration) changes in response to the perturbation of an adjustable parameter. Dimensionless-scaled sensitivities allow for the comparison of the importance of different observations with respect to the estimation of a single 
parameter. Furthermore, it can be used to compare the importance of different parameters toward the computation of a single simulated head or concentration or head value. Composite-scaled sensitivities css calculated for all observations points are computed using equation (8) [e.g., Hill, 1992]:

$$
\operatorname{css}_{j}=\sum_{i=1}^{\mathrm{ND}}\left[\frac{\left.\left(\mathrm{dss}_{i j}\right)^{2}\right|_{b}}{\mathrm{ND}}\right]^{1 / 2},
$$

where ND is the total number of observation points.

[34] The composite-scaled sensitivity reflects the total amount of information provided by the observations for the estimation of one parameter [Hill and Tiedeman, 2007].

[35] Initial estimates of hydraulic parameters are derived from sieve analyses [Beyer, 1964] and pumping tests (Table 1). Due to the correlation between hydraulic conductivity and specific storage, the specific storage is not included into the inversion process and set homogenously to $4.5 \times 10^{-5} \mathrm{~m}^{-1}$, as determined from several pumping tests.

[36] The sensitivities calculated in PEST can also be used to assess the relative worth of data. In this study, data worth is assessed in terms of the calculated reduction in model predictive uncertainty that would be accrued through inclusion of extra information furnished by a measurement or series of measurements at a location and a specific time $t$ [e.g., Doherty, 2010; Dausman et al., 2010; Moore and Doherty, 2005]. This can be calculated as follows:

$$
\sigma_{s}^{2}=\mathbf{y}^{t} \mathbf{C}(p) \mathbf{y}-\mathbf{y}^{t} \mathbf{C}(p) \mathbf{X}^{t}\left[\mathbf{X} C(p) \mathbf{X}^{t}+\mathbf{C}(\varepsilon)\right]^{-1} \mathbf{X} C(p) \mathbf{y},
$$

where $\sigma_{s}^{2}$ is the predicted uncertainty, $\mathbf{C}(p)$ is the parameter covariance matrix based on prior parameter knowledge, $\mathbf{X}$

Table 1. Hydraulic Parameter Estimates Based on the Joint Thermal-Hydraulic and Solute Transport Model and a Sieve

\begin{tabular}{|c|c|c|}
\hline Parameter & $\begin{array}{l}\text { Initial Estimate } \\
\text { From Field } \\
\text { Investigation }^{\mathrm{a}}\end{array}$ & $\begin{array}{c}\text { Model } \\
\text { Estimation }\end{array}$ \\
\hline$\%$ silt $\mathrm{b} / \%$ quartz ${ }^{\mathrm{c}}$ (layer 1 ) & $65 / 35$ & \\
\hline$\%$ silt $/ \%$ quartz (layer 2 ) & $17 / 83$ & \\
\hline$\%$ silt $/ \%$ quartz (layer 3 ) & $5 / 95$ & \\
\hline$\%$ silt $/ \%$ quartz (layer 4 ) & $4 / 96$ & \\
\hline$\%$ silt $/ \%$ quartz (layer 5 ) & $5 / 95$ & \\
\hline$\%$ silt $/ \%$ quartz (riverbed sediments) & $1 / 99$ & \\
\hline$K_{h} ; K_{v}$ silt (layer $1 ; \mathrm{m} \mathrm{d}^{-1}$ ) & 0.04 & $0.031 ; 0.025$ \\
\hline$K_{h} ; K_{v}$ fine sand (layer $2 ; \mathrm{m} \mathrm{d}^{-1}$ ) & 0.9 & $1.03 ; 0.51$ \\
\hline$K_{h} ; K_{v}$ middle sand (layer $3 ; \mathrm{m} \mathrm{d}^{-1}$ ) & 4 & $3.59 ; 2.15$ \\
\hline$K_{h} ; K_{v}$ coarse sand (layer $4 ; \mathrm{m} \mathrm{d}^{-1}$ ) & 23 & $27.30 ; 31.40$ \\
\hline$K_{h} ; K_{v}$ fine gravel (layer $\left.5 ; \mathrm{m} \mathrm{d}^{-1}\right)$ & 33 & $39.15 ; 39.54$ \\
\hline$K_{h} ; K_{v}\left(\right.$ riverbed sediments $\left.; \mathrm{m} \mathrm{d}^{-1}\right)$ & 32 & $40.73 ; 30.55$ \\
\hline Porosity (layer 1) & 0.35 & 0.30 \\
\hline Porosity (layer 2) & 0.37 & 0.45 \\
\hline Porosity (layer 3) & 0.39 & 0.45 \\
\hline Porosity (layer 4) & 0.39 & 0.28 \\
\hline Porosity (layer 5) & 0.38 & 0.45 \\
\hline Porosity (riverbed sediments) & 0.35 & 0.12 \\
\hline
\end{tabular}
Analysis Using Beyer [1964]

${ }^{\mathrm{a}}$ Field data are mean hydraulic conductivities of both, vertical and horizontal conductivities.

${ }^{\mathrm{b}}$ Silt contains clay and silt components.

${ }^{\mathrm{c}} \mathrm{Q}$ uartz contains the sand and gravel components. is the model matrix, and $\mathbf{C}(\varepsilon)$ is the covariance matrix of measurement noise.

[37] This formulation has been implemented via the PEST utility software linear predictive uncertainty analysis (PREDUNC) [Doherty, 2010] and used unmodified in this work. An important characteristic of equation (9) is that it does not contain parameter values or measurements or model output values. Instead only the sensitivities of the model outputs to parameters under calibration and predictive conditions are considered, as constrained by the matrix $\mathbf{X}$ and the vector $\mathbf{y}$, respectively. The existing calibration data set can therefore be augmented by proposed new data, by simply adding rows to the $\mathbf{X}$ matrix. The reduction in the resulting $\sigma_{s}^{2}$ as a result of such additions to the $\mathbf{X}$ matrix is a measure of the worth of such additions to the calibration data set.

\section{Results and Discussions}

\subsection{Estimated Hydraulic, Thermal, and Solute Transport Properties}

[38] The joint inversion of head, temperature, and acesulfame data resulted in plausible models that match well with the observed values at most locations (Figures 4, 5a, $5 \mathrm{~b}$, and 6). Table 1 lists the model-derived estimates of the hydraulic parameters and the corresponding field-measured values. The comparison of the values shows that measured and model-based estimates of horizontal hydraulic conductivities were in approximately the same range. Note that the vertical hydraulic conductivities were not determined by field measurements, while being included in the model inversion process. Estimated vertical conductivities were reduced by a factor between 2 and 5 compared with the estimates for horizontal hydraulic conductivities. Although measured total porosities were found to be in the same range for all the investigated model zones of the aquifer, a

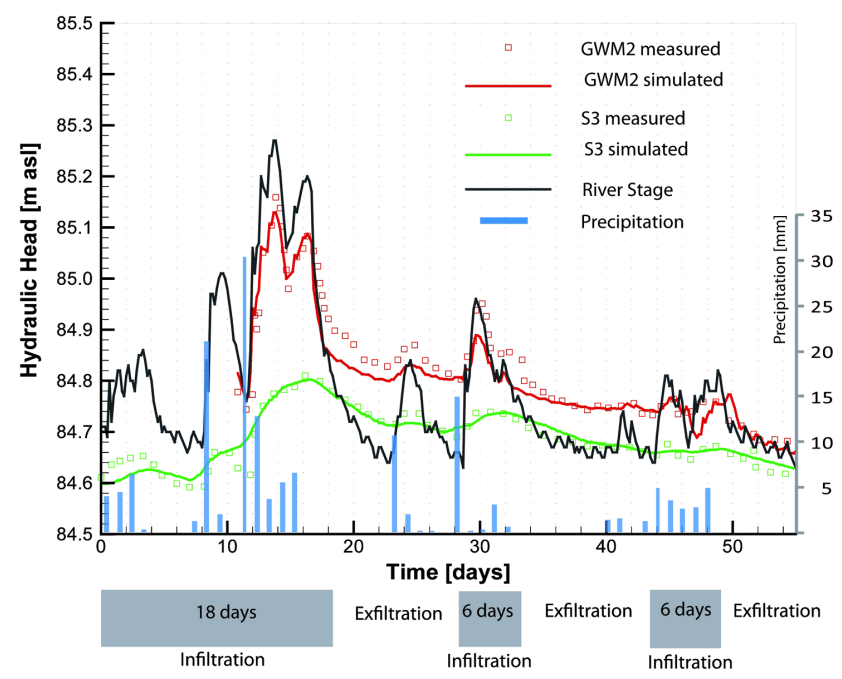

Figure 4. River water level, precipitation, and measured hydraulic and simulated pressure heads. Gray regions mark periods of influent conditions, i.e., the occurrence of flow from the stream into the aquifer. 
(a)
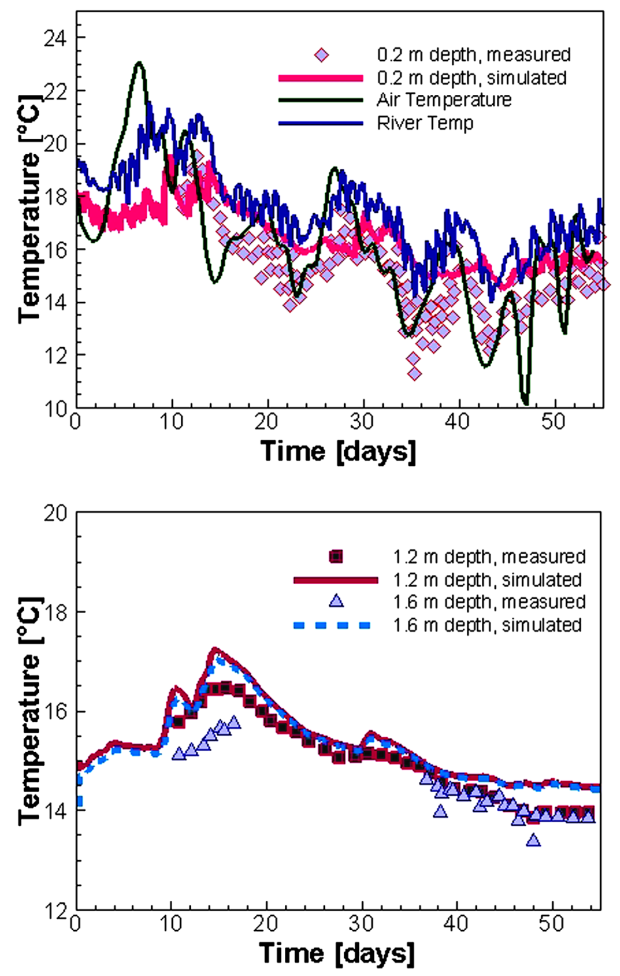

(b)
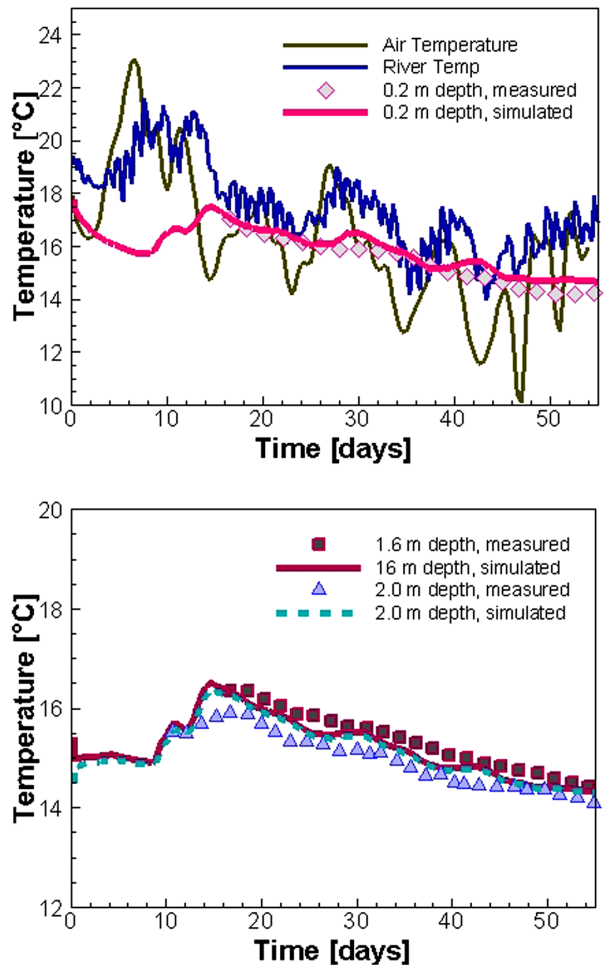
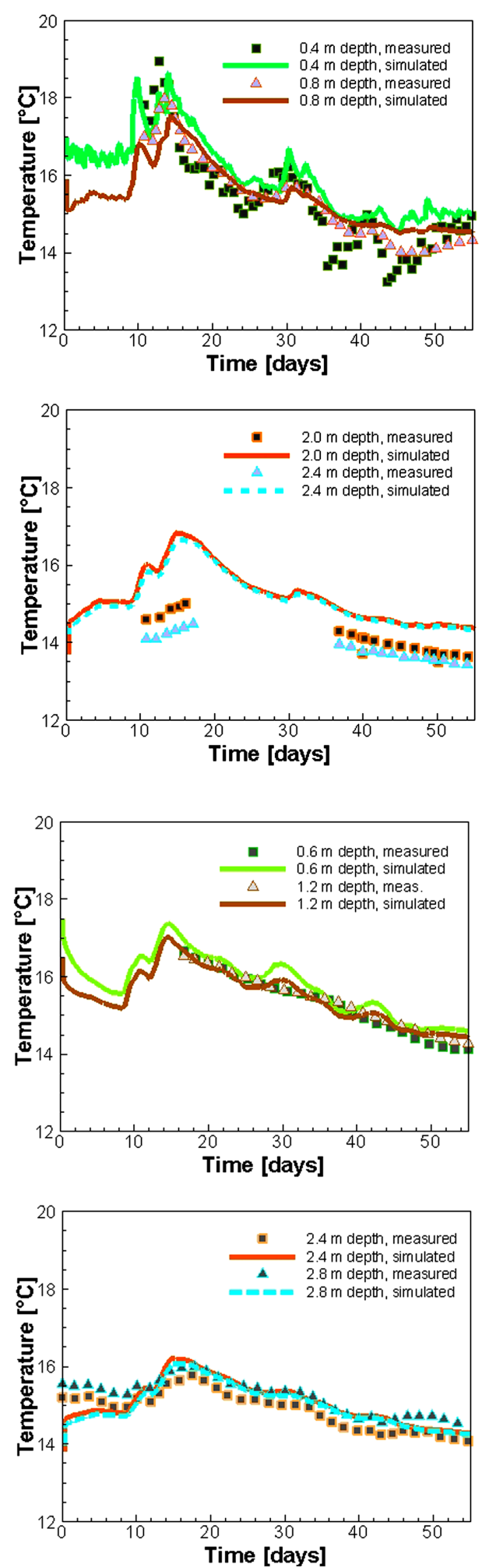

Figure 5. Measured surface water and air temperature, multilevel temperature data sets, and simulated temperature profiles (dots are measured data, lines are model results): (a) TML1 (beneath the river bed) and (b) TML2 (3.4 m horizontal from the river bank). 

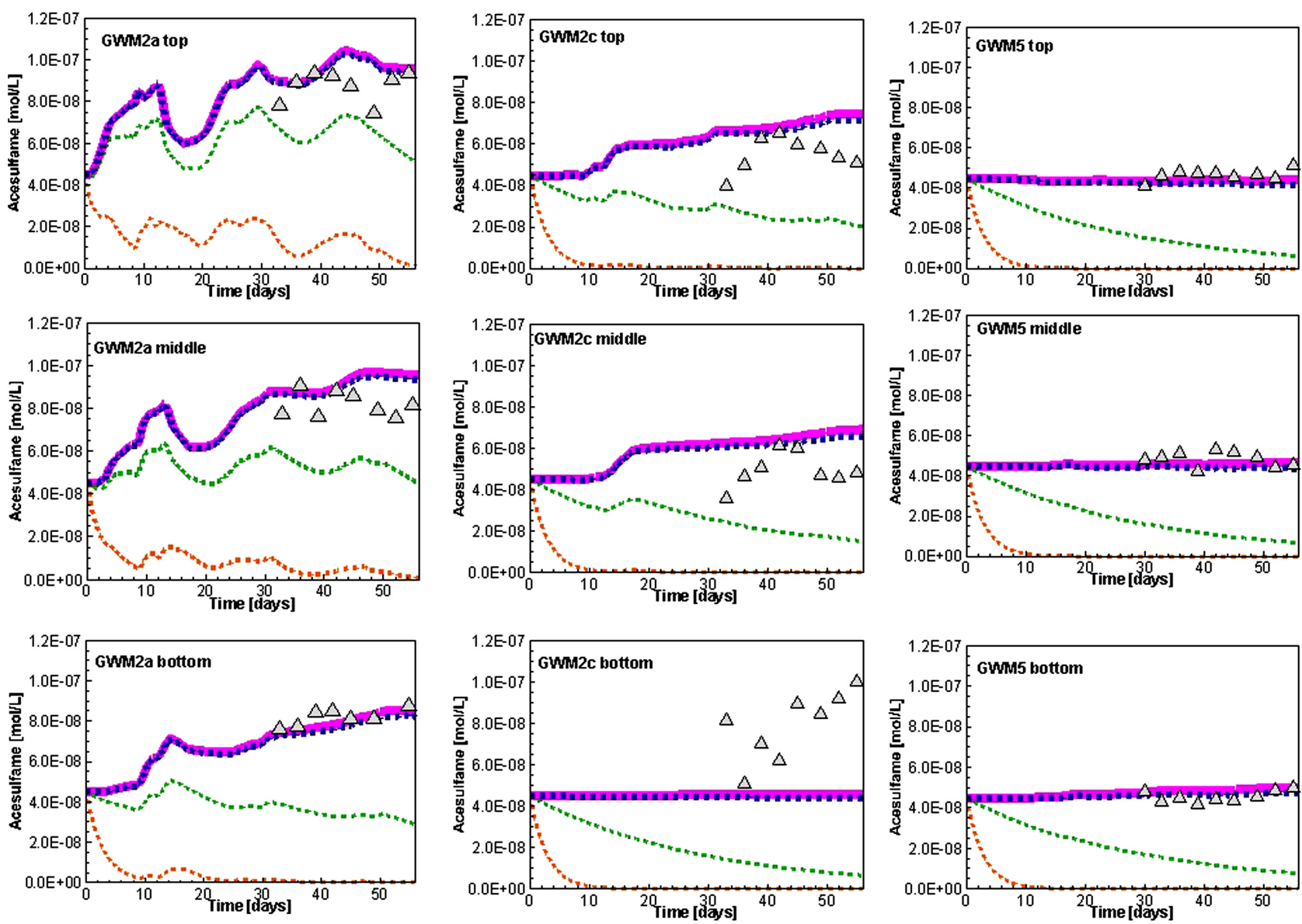

Figure 6. Measured (black triangles) and simulated (line) acesulfame concentration along the investigated transect. The solid magenta line shows model results for the case that assumes absence of acesulfame degradation. Dotted lines indicate variations with a first-order degradation using a half-life of 2 days (orange line), a half-life of 20 days (green line), and a half-life of 2 years (blue line).

more variable effective porosity among the model layers was determined during the model calibration (Table 1).

[39] Estimated effective porosities changed from $12 \%$ for the clogging layer and increased to $28 \%-45 \%$ for the sand and gravel units. The variations of the estimated porosities result in corresponding variations of the estimated thermal model parameters. Overall, the model estimated thermal conductivities and specific heat capacities are within realistic boundaries. The thermal retardation associated with these thermal properties varies between 3.2 and 5.4 (Table 2), which is in the range of earlier reported thermal retardation factors [e.g., Therrien et al., 2010]. The estimated longitudinal and vertical transverse dispersivity were approximately $0.6 \mathrm{~m}$ and $0.014 \mathrm{~m}$, respectively, which plausibly correspond to the small scale of the investigated domain.

\subsection{Characteristics of Temperature Transport}

[40] The study period was a highly transient period during which the Schwarzbach regularly alternated between losing and gaining conditions. The start of the investigated period was characterized by losing conditions and included a flash flood between days 12 and 18 (Figure 4). Subsequently, a switch to gaining conditions was observed between days 18 and 29. After day 30, a second losing period prevailed for approximately 6 days, followed by a third losing-dominated period between days 44 and 50 . Gaining periods were at several occasions interrupted by short infiltration events that lasted for only a few hours. Surface water levels responded within a few hours after the onset of short-lived rain events. Losing conditions persisted over several days and thus generated notable mass fluxes toward the groundwater system, mostly during periods when rain intensity exceeded $15 \mathrm{~mm} \mathrm{~d}^{-1}$ (Figure 4).

[41] The calibrated numerical flow model reproduces those observed hydraulic heads and their dynamic changes generally very well. This includes the hydraulic heads measured at S3, i.e., $23 \mathrm{~m}$ downstream from the river as well as the heads measured closer to the river, at GWM2. The measured hydraulic gradients between GWM2 and the river and GWM2 and S3 indicate that, under effluent conditions, a local water divide develops temporally near the river bank.

[42] The measured surface water temperatures followed air temperatures during most parts of the investigated study period, though with less variability. However, during periods with distinctly higher or lower air temperatures, i.e., above $20^{\circ} \mathrm{C}$ or below $14^{\circ} \mathrm{C}$, surface water temperatures were not identical with measured air temperatures. 
Table 2. Thermal and Solute Transport Parameter Estimates by the PEST Models and Thermal Parameter From a Sieve Analysis Analyzed With the Johansen [1975] Approach

\begin{tabular}{lcc}
\hline Parameter & $\begin{array}{c}\text { Initial Estimation } \\
\text { From Sieve Analysis }\end{array}$ & $\begin{array}{c}\text { Model } \\
\text { Estimation }\end{array}$ \\
\hline$\alpha_{L}(\mathrm{~m})$ & & 0.6 \\
$\alpha_{T}(\mathrm{~m})$ & & 0.014 \\
$\lambda_{m}{ }^{a}\left(\mathrm{~W} \mathrm{~m}^{-1} \mathrm{~K}^{-1}\right)$ & $2.1-2.8$ & $2.2-3.7$ \\
$c_{m}{ }^{a}\left(\mathrm{~J} \mathrm{~kg}^{-1} \mathrm{~K}^{-1}\right)$ & $2070-2210$ & $1687-2339$ \\
$R_{t h}{ }^{a}(-)$ & $2.4-3.6$ & $2.6-3.1$ \\
\hline
\end{tabular}

${ }^{\mathrm{a}}$ Variance is given by differences of the porosity and silt/quartz content of the five investigated layers.

[43] Figure 5a shows that, up to a depth of $0.4 \mathrm{~m}$ beneath the Schwarzbach, the characteristics of the measured groundwater temperature variations (TML1) closely follow those of the surface water temperatures. At greater depths between 0.8 and $2.0 \mathrm{~m}$, the diurnal temperature oscillations are dampened within the groundwater; however, characteristic maximal and minimal river temperatures can still be retrieved. Beneath $2 \mathrm{~m}$, diurnal river water temperature oscillations have dissipated and only longer-term temperature trends are reflected in the groundwater. Similarly, the measured temperature data collected in lateral proximity, i.e., at the river bank (TML2), show slight diurnal temperature variations up to a depth of $2 \mathrm{~m}$ (Figure 5b). These are less distinct compared with those observed at shallower depth below the Schwarzbach.

[44] Similarly, the measured temperature data collected in lateral proximity, i.e., at the river bank (TML2), show slight diurnal temperature variations up to a depth of $2 \mathrm{~m}$ (Figure 5b). These are less distinct compared with those observed shallow below the Schwarzbach. All measured temperature variations are generally well matched $y$ the calibrated thermal model, except for the observations made at $0.2 \mathrm{~m}$ depth. In particular, the diurnal groundwater temperature fluctuations are well reproduced at both locations, i.e., beneath the streambed and bank.

[45] The calibrated model was used to estimate the infiltration velocities that prevailed during the study period. During the flash flood, an infiltration velocity of up to $0.09 \mathrm{~m} \mathrm{~d}^{-1}$ developed when a hydraulic gradient of 0.5 prevailed between the surface water and groundwater. Quickly within a few days after the flash flood event, the infiltration velocity decreased again to the average infiltration velocity. Under gaining conditions and with a hydraulic gradient of -0.3 , a maximum discharge velocity of $0.04 \mathrm{~m} \mathrm{~d}^{-1}$ was computed. For the investigated period of 2 months, which contained losing and gaining periods, the mean infiltration velocity was approximately $0.02 \mathrm{~m} \mathrm{~d}^{-1}$.

\subsection{Characteristics of Acesulfame Transport}

[46] The shallow samples from GWM2a and GWM2c provided acesulfame concentrations, which, on the basis of a few samples, appear to mirror those observed within the surface water. However, unlike the temperature source term, which was based on continuous monitoring data, continuous acesulfame source concentrations were instead estimated on the basis of the observed inverse relationship between surface water acesulfame concentrations and the stream discharge. Therefore, there is some uncertainty in the source concentrations of acesulfame, which can be expected to cause increased discrepancies between simulated and measured acesulfame concentrations in the groundwater (Figure 6). Furthermore, the signatures introduced by temperature variations were much more distinct than those observed for acesulfame. For example, acesulfame concentrations at GWM5 remained essentially constant over the whole observation period at all three monitored depth intervals. Also, concentration variations at GWM2a were difficult to reproduce with the model. Nevertheless, the simulated breakthrough curves that were obtained with the automatically calibrated transport model show for most monitoring locations (e.g., GWM2a) a reasonable match with the measured acesulfame data, while deviations persist at other locations (e.g., GWM2c). At the top and middle levels of GWM2c, fluctuations of the acesulfame concentrations were observed that correspond to the acesulfame input function. These fluctuations were not reproduced by the transport model. However, they were also not measured and simulated at GWM2a that is located closer to the river bank than GWM2c.

[47] Measured concentrations were well matched with the model at GWM5 that is located at some distance to the river bank. At a depth of $13 \mathrm{~m}$ below surface, measured acesulfame concentrations at an increased level of up to $1 \times 10^{-7} \mathrm{~mol} \mathrm{~L}^{-1}$ were found. These higher concentrations presumably originated from earlier infiltration events and were not well matched by the model. Assigning higher initial acesulfame concentration toward the bottom of the aquifer would have improved the agreement between simulations and measurements. However, as the infiltration events that occurred during the study period did not penetrate to the deeper parts of the aquifer (Figure 7), a homogenous distribution of the initial acesulfame concentration was kept for simplicity.

[48] The results shown in Figure 6 represent simulations in which the acesulfame degradation rate constant (i.e., half-life) was included as an adjustable parameter during the model calibration that was jointly constrained by head, temperature, and acesulfame data. The resulting, optimized degradation rate constant was $1 \times 10^{-3} \mathrm{~d}^{-1}$, which corresponds to a half-life of approximately 2 years. In Figure 6, these results are shown in comparison with several other cases that assumed shorter a half-life of 200,20,2, and 0.2 days, respectively. It is evident that the simulated breakthrough curves for the relatively fast degradation rates provide unacceptable matches. However, even the simulation that assumes an acesulfame half-life of 200 days clearly underestimates the measured concentrations throughout the period for which measured data were available, in particular, at GWM5. Overall, this provides further evidence for the previously suggested assumption that acesulfame degradation was either absent or very slow, which contrasts the behavior of other artificial sweeteners such as cyclamate [Buerge et al., 2009].

\subsection{Residence Times and Wastewater-Related Mass Fluxes}

[49] The age simulations with the calibrated model illustrate the spatial infiltration patterns that develop during the 55 day long study period. As illustrated in Figure 7, the three infiltration events that occurred during the monitored 


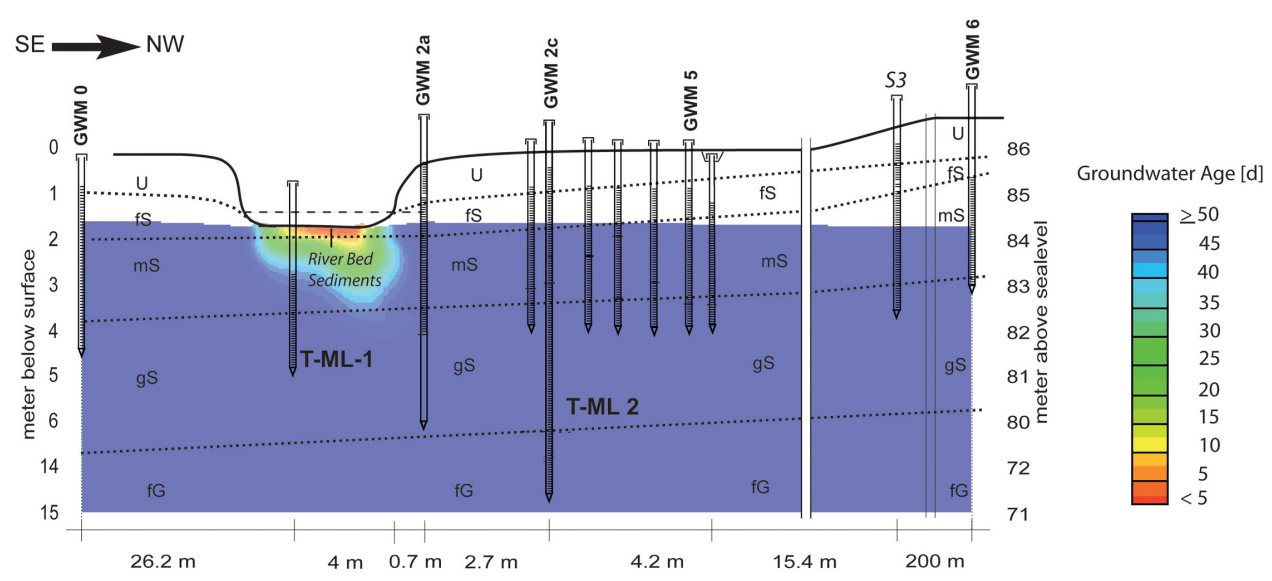

Figure 7. Simulated "groundwater ages" for the model that was jointly constrained by head, temperature, and acesulfame data, whereby the simulated age corresponds to the "age since start of simulation."

period resulted in the migration of surface water to a depth of $2.5 \mathrm{~m}$ below the water table and $1 \mathrm{~m}$ laterally in the downgradient direction. This means that even if longer effluent conditions prevail the inflow of fresh groundwater by the regional groundwater flow from the upgradient direction will not result in a strong dilution of the downstream surface water plume.

\subsection{Prediction of Uncertainty and Data Worth Assessment}

[50] To elucidate the value of the acesulfame data collected in the groundwater for the quantification of acesulfame mass fluxes, one approach taken was to compare the model output uncertainty using various data (sub)sets to constrain the model calibration. For the purpose of this comparison, it was assumed that the model used all available data (i.e., temperature data, piezometric pressure heads, and acesulfame concentrations) for the model calibration. This calibrated model was then used as the base case. Using equation (13), a prior parameter covariance matrix informed by the range of field values in Tables 1 and 2, and literature values, the uncertainty of this base case simulation was estimated, resulting in very small calculated uncertainty ranges. This was used to compare the standard error of outputs if (i) only head data (ii), only acesulfame data, and (iii) only temperature data were alternatively used to constrain the PESTbased automatic model calibration (Figure 8). The calculated error increases indicate that a model that used solely acesulfame data for the calibration would have the greatest standard error, whereas the model that was calibrated by solely using piezometric pressure head data as constraints would have significantly less error in the mass flux estimates. The model that resulted from the calibration using temperature data as sole constraints gave very similar results to the calibrated base model that used a joint inversion of acesulfame, temperature, and pressure head data.

[51] This analysis depicted in Figure 8 can be compared with the analyses of relative data worth of all observations in terms of a mass flux prediction using the methodology encapsulated in equation (13). The analysis was undertaken in two ways: first, the increase in uncertainty that occurs if an observation is removed from the calibration constraints was assessed (i.e., starting conditions assume all observations are available), and, second, in terms of the reduction in uncertainty that occurs by adding an observation to the data set (i.e., starting conditions assume no observations are available). In both of these cases, the observations can either be existing or also future nominal observations, but we focused on the existing monitoring data set.

[52] Figure 9 depicts the results of these analyses. A very significant increase in uncertainty of surface water-groundwater mass flux predictions would be incurred if the shallow temperature measurements at TML1 (i.e., TML1_0.2, TML1_0.4, TML1_0.8, and TML_1.2) were removed. Therefore, the analysis indicates that temperature measurements at these points had the greatest "worth" in terms of the mass flux prediction. Removing the temperature measurements at TML2 and the pressure head measurements would also

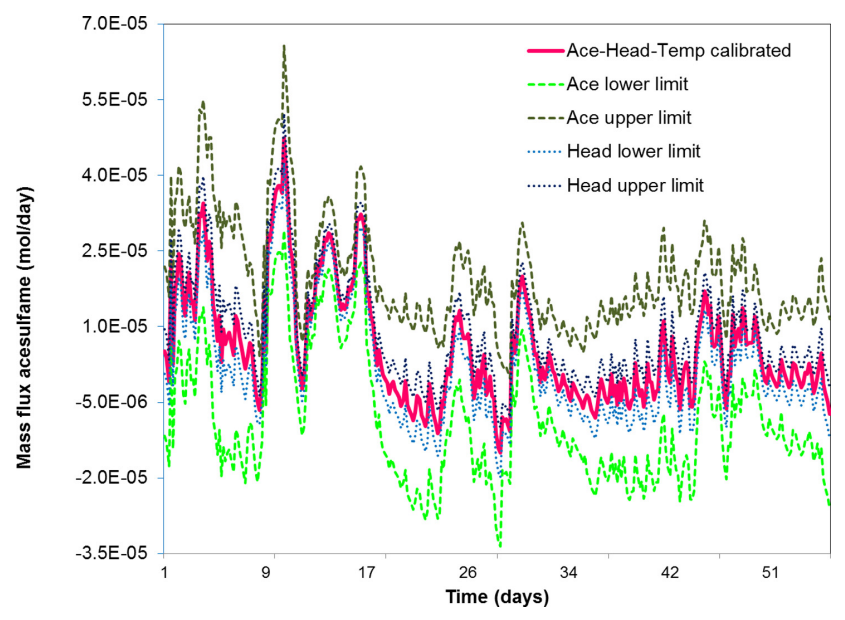

Figure 8. Simulated mass flux of acesulfame within the hyporheic and riparian zone. The base model (solid red line) represents the case where temperature, acesulfame, and head data were jointly used as constraints. The case in which only acesulfame data were used is given by the dotted green lines, whereas the case in which only piezometric pressure heads were used is indicated by the dotted blue line. 


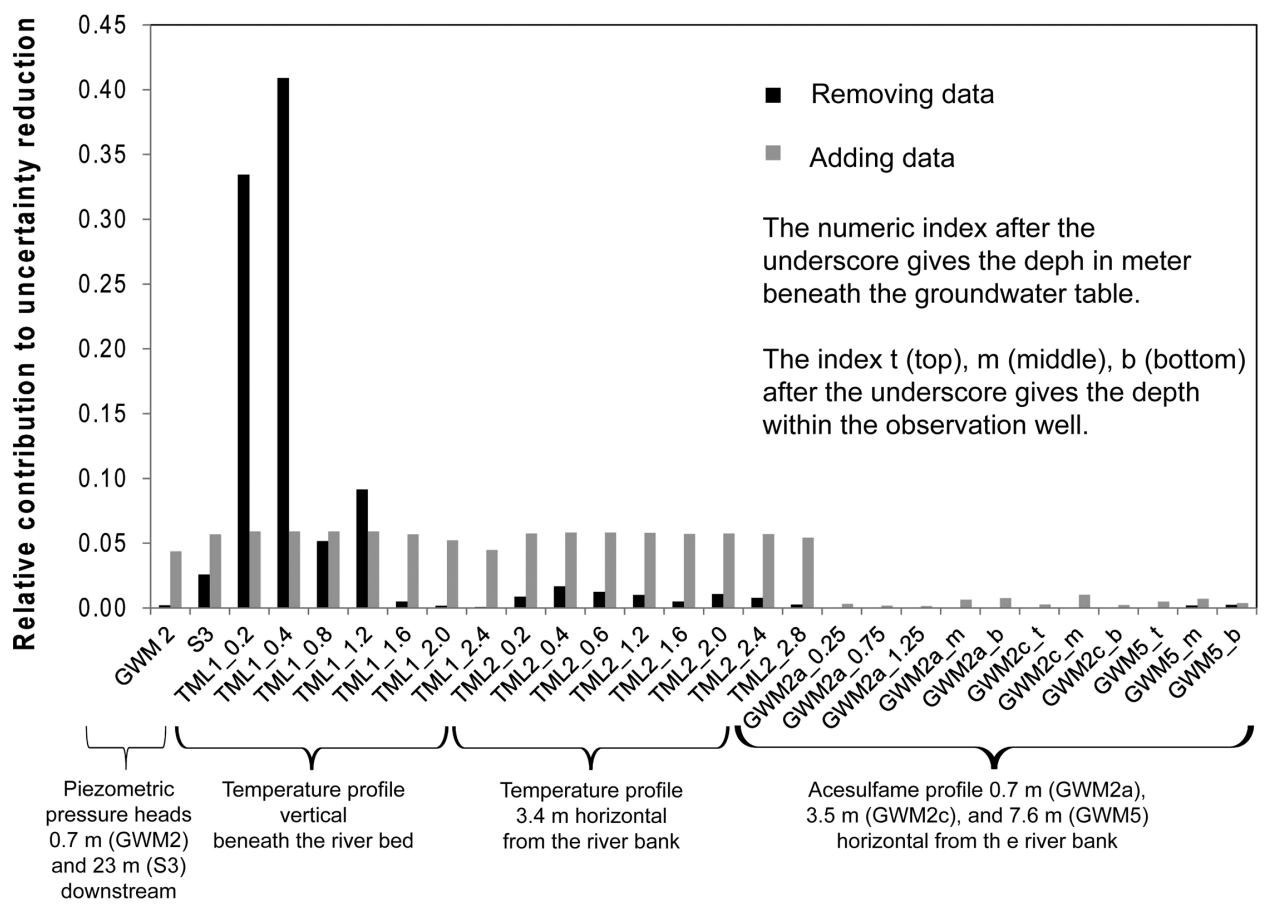

Figure 9. Relative worth of monitored data in terms of reducing the uncertainty of a surface watergroundwater mass flux prediction. Data worth is calculated in two ways, first by beginning with no observations and adding an observation one at a time and, second, by beginning with all observations and removing an observation at a time. The index after the observation location (GWM2, S3, TML1, TML2, GWM2a, GWM2c, GWM5) is giving the depth in meter, while $t, \mathrm{~m}$, and $\mathrm{b}$ indicate top, middle, and bottom, respectively.

increase the uncertainty of the prediction but to a far lesser extent. Removing the acesulfame data had little impact on the reliability of the surface water-groundwater mass flux prediction.

[53] The second analysis, where the starting condition was that no observations were available, and each observation was added one at a time, indicated that the measurements of temperature and pressure head contributed similar reductions in uncertainty (e.g., of similar data worth). Once again the acesulfame data had little impact on the mass flux prediction. Clearly, for this surface water-groundwater mass flux prediction, results indicate the importance of temperature measurements and, to a lesser extent, head data, compared with that of the acesulfame data. Therefore, although acesulfame is important in identifying provenance of a flux, it is not suited to quantify the magnitude of the flux. However, the relative worth of these observations could alter if different predictions, other than mass flux, were selected, and if cost considerations did not limit the frequency of acesulfame measurements. One further aspect that will impact the value of the tracer is the distance of the observation location from the stream. For example, the nonconservative behavior of temperature will erode the information content of this tracer, when monitored further away from the stream. In contrast, because of its conservative behavior, acesulfame will distinguish between surface water and groundwater at greater distances from the stream.

[54] Nevertheless, the prediction focused assessment of data worth provides an important contrast to the sensitivity analysis discussed in the next section, which instead explores the usefulness of data to constrain a calibration, rather than to make a specific prediction more reliable.

\subsection{Sensitivity Analysis of Pressure Heads, Temperature, and Artificial Sweetener as Environmental Tracers}

[55] A sensitivity analysis was used to provide additional insights into and a quantitative measure of the usefulness of the various observations that were used to constrain the model calibration. As part of this analysis, we determined (i) sensitivity coefficients that were computed with respect to data from different observation times, (ii) different observation locations, (iii) sensitivity coefficients with respect to infiltration velocities, and (iv) sensitivity coefficients with respect to various model parameters.

[56] The sensitivity analysis reveals that dimensionlessscaled sensitivities are highest for temperature data that were measured vertically beneath the riverbed. The computed sensitivities show to successively decrease with depth. In the calibration, temperature fluctuations measured directly beneath the riverbed yield the most valuable observations to calibrate the thermal transport model. Temperature data are more valuable when recorded during periods of high infiltration velocities, and sensitivities were highest directly after the maximum infiltration velocity occurred. This means that when employing temperature data to constrain model predictions and estimations, particularly, the period after flood or high water events should be recorded 
and used for the model calibration. The illustrated behavior of the sensitivities of the temperature data can help to collect the most valuable data in the field when short-time monitoring campaigns are designed. For the data set analyzed here, temperature data collected in lateral direction from the river bank constrained the model calibration only to a relatively minor extent.

[57] Dimensionless-scaled sensitivities of piezometric pressure heads were also found to be low, indicating that their contribution toward the parameter estimation process is clearly less important than the temperature measurements below the Schwarzbach.

[58] Dimensionless-scaled sensitivities of acesulfame were low compared with the sensitivity of temperature measured beneath the riverbed but higher than the sensitivities of piezometric pressure heads. Computed sensitivities of the temperatures were closely linked with the hydraulic flow patterns, whereas the sensitivities of acesulfame largely remained unaffected by the variability of the infiltration velocities during the 55 days of simulation time. This means, sensitivities of acesulfame were mostly independent of the prevailing hydraulic conditions and decreased with observation time and depth.

[59] Composite-scaled sensitivity coefficients with respect to model parameters were computed for the model that was calibrated via joint inversion of hydraulic, thermal, and acesulfame data. For this model, the highest sensitivities were calculated for hydraulic conductivities, whereby the horizontal hydraulic conductivities were found to be more sensitive compared with the vertical hydraulic conductivities. In comparison, porosities were found to be less sensitive than the hydraulic conductivities. The highest sensitivities of all parameters were computed for the horizontal hydraulic conductivity of layer 2 (fine sand), whereas highest sensitivities of the porosity and the vertical hydraulic conductivity were calculated for layer 3 (middle sand). This indicated that layer 2 was mostly responsible for the horizontal solute and temperature transport, and layer 3 influenced vertical transport direction.

[60] Thermal parameters were found to be moderately sensitive, whereby the thermal conductivity is more important than the specific heat. As a consequence of the relatively small values used for hydrodynamic dispersion, the impact on the predictions of temperature and solute transport is small, as indicated by the computed low sensitivity. Similarly, the sensitivity of the estimated initial concentrations of acesulfame was found to be very low under the investigated conditions. This is of high importance for the assessment of the model reliability, as spatially varying initial concentrations have probably prevailed but were not considered in the absence of detailed data, as discussed earlier. The first-order decay rate constant of acesulfame has a high sensitivity for the model results, as by assuming a half-life of less than 200 days resulted in a strong underestimation of acesulfame concentrations.

\section{Conclusion}

[61] A model-based analysis of measured head, multilevel temperature, and acesulfame breakthrough data was used to assess the suitability of acesulfame to trace wastewaterrelated mass fluxes within the hyporheic and riparian zone.
The results indicate that, for the investigated time period and under the prevailing hydrological and geochemical conditions, acesulfame behaved essentially conservatively and could therefore be used as a reliable indicator of provenance.

[62] However, at the study site, like presumably at many other sites in densely populated regions, elevated background concentrations of acesulfame exist in the aquifer beneath and even upstream of the investigated stream. This compromises the suitability of acesulfame as a stand-alone tracer to track waste-water-related mass fluxes under such rather complex hydrodynamic conditions. During the investigated period, the acesulfame load released from the WWTP into the surface water changed only moderately. Therefore, the acesulfame concentrations found within the groundwater also showed only small variations, and measured concentration changes did not substantially assist the identification of the flow patterns that occurred during the study period within the hyporheic and riparian zone. Analyses indicated that, because of this absence of significant fluctuation in the input function of acesulfame, additional measurement types are important for reliable estimates of surface water fluxes and mass fluxes of surface-water-related micropollutants into the hyporheic and riparian zone. In particular, diurnal surface water temperature fluctuations were displayed sensitively by groundwater temperature oscillations beneath the riverbed.

[63] Model sensitivities revealed the receptive nature of vertical temperature profiles to the hyporheic and riparian flow pattern and changes of infiltration velocities. This is particularly important when capturing high-stage events when the greatest quantities of micropollutants will migrate into the groundwater. These results suggest the use of vertical temperature profiles beneath the riverbed would enhance future monitoring campaigns. The analyses indicated that computed mass fluxes derived from a model that was only constrained by acesulfame data would be less reliable than those where the model was additionally constrained with temperature profiles.

[64] The analysis of the measured data further supports the previously suggested assumption that acesulfame behaves indeed like a conservative tracer in groundwater systems, at least under similar geochemical conditions as at our study site. However, acesulfame might show a different behavior if (i) the long-term conservative behavior is addressed, (ii) higher acesulfame concentrations are released from WWTP into the surface water and thus will reach the hyporheic zone, or (iii) aerobic conditions may prevail in the hyporheic and riparian zone. Further investigations analyzing these uncertainties will improve our ability to assess the fate of acesulfame in the environment.

[65] The results also suggest that using acesulfame as a stand-alone tracer may be problematic. Thus, collecting vertically resolved temperature data beneath the riverbed should additionally be considered when investigating the fate of surface-water-related mass fluxes of micropollutants into the groundwater.

[66] Acknowledgments. The research benefited greatly from the scientific discussion and technical support of Johannes Stegner and Christoph Kludt (both from Technical University of Darmstadt, Germany), Matthias Piepenbrink (ERM GmbH, Germany), and Evelien Martens (CSIRO, Australia) 


\section{References}

Anderson, M. P. (2005), Heat as a groundwater tracer, Ground Water, 43(6), 951-968.

Angermann, L., J. Lewandowski, J. H. Fleckenstein, and G. Nützmann (2012), A 3D analysis algorithm to improve interpretation of heat pulse sensor results for the determination of small-scale flow directions and velocities in the hyporheic zone, J. Hydrol., 475, 1-11.

Anibas, C., J. H. Fleckenstein, N. Volze, K. Buis, R. Verhoeven, P. Meire, and O. Batelaan (2009), Transient or steady-state? Using vertical temperature profiles to quantify groundwater-surface water exchange, Hydrol. Process., 23(15), 2165-2177.

Appelo, C. A. J., and D. Postma (2005), Geochemistry, Groundwater and Pollution, A. A. Balkema, Leiden, Netherlands.

Berthold, G., and M. Hergesell (2005), Flächendifferenzierte Untersuchungen zu möglichen Auswirkungen einer Klimaänderung auf die Grundwasserneubildung in Hessen. INKLIM 2012-Integriertes Klimaschutzprogramm, Abschlussbericht Hessisches Landesamt für Umwelt und Geologie, Wiesbaden.

Beyer, W. (1964), Zur Bestimmung der Wasserdurchlässigkeit von Kiesen und Sanden aus der Kornverteilung, Wasserwirt. Wassertech., 14, 165 169 , Berlin-Ost.

Brookfield, A. E., E. A. Sudicky, Y.-J. Park, and B. Conant Jr. (2009), Thermal transport modelling in a fully integrated surface/subsurface framework, Hydrol. Process., 23, 2150-2164.

Buerge, I. J., H. R. Buser, M. Kahle, M. D. Müller, and T. Poiger (2009), Ubiquitous occurrence of the artificial sweetener acesulfame in the aquatic environment: An ideal chemical marker of domestic wastewater in groundwater, Environ. Sci. Technol., 43(12), 4381-4385.

Christensen, J. H., et al. (Eds.) (2007), Climate Change 2007: The Physical Science Basis. Contribution of Working Group I to the Fourth Assessment Report of the Intergovernmental Panel on Climate Change, Cambridge Univ. Press, Cambridge, U. K.

Conant, B. (2004), Delineating and quantifying ground water discharge zones using streambed temperatures, Ground Water, 42(2), 243-257.

Daughton, C. G., and T. A. Ternes (1999), Pharmaceuticals and personal care products in the environment: Agents of subtle change, Environ. Health Perspect., 107(6), 907-938.

Dausman, A. M., J. Doherty, C. D. Langevin, and M. C. Sukop (2010), Quantifying data worth toward reducing predictive uncertainty, Ground Water, 48(5), 729-740.

de Marsily, G. (1986), Quantitative Hydrogeology, Academic, San Diego, Calif.

Doherty, J. (2010), PEST - Model-Independent Parameter Estimation. User's Manual, 5th ed., Watermark Numer. Comput., Brisbane, Australia.

Domenico, P. A., and F. W. Schwartz (1990), Physical and Chemical Hydrogeology, Wiley, New York.

Engelhardt, I., M. Piepenbrink, N. Trauth, S. Stadler, C. Kludt, M. Schulz, C. Schüth, and T. Ternes (2011), Comparison of tracer methods to quantify hydrodynamic exchange within the hyporheic zone, J. Hydrol., 400, 255-266.

Goode, D. J. (1996), Direct simulation of groundwater age, Water Resour. Res., 32(2), 289-296.

Gregory, S. V., F. J. Swanson, W. A. Mc Kee, and K. W. Cummins (1991), An ecosystem perspective of riparian zones. Bioscience, 41, 540-551.

Harbaugh, A. W. (2005), MODFLOW-2005, the U.S. Geological Survey modular ground-water model-The Ground-Water Flow Process, U.S. Geol. Surv. Tech. Methods 6-A16. USGS Reports, Reston, Va., U.S.A.

Heberer, T., (1995), Identification and Quantification of Pesticide Residues and Environmental Contaminants in Ground and Surface Water Applying Capillary Gas Chromatography-Mass Spectrometry (in German), Wissenschaft \& Technik, Berlin.

Heberer, T., (2002), Tracking pharmaceutical residues from municipal sewage to drinking water, J. Hydrol., 266, 175-189.

Hecht-Méndez, J., N. Molina-Giraldo, P. Blum, and P. Bayer (2010), Evaluating MT3DMS for heat transport simulation of closed geothermal systems, Ground Water, 48(5), 741-756.

Hill, M. C., (1992), A computer program (MODFLOWP) for estimating parameters of a transient, three-dimensional groundwater flow model using nonlinear regression, U.S. Geol. Surv. Open File Rep. 91-484.

Hill, M. C., and C. R. Tiedeman (2007), Effective Groundwater Model Calibration, With Analysis of Sensitivities, Predictions, and Uncertainty, Wiley \& Sons, Inc., Hoboken, N. J.

Hill, M. C., R. L. Cooley, and D. W. Pollock (1998), A controlled experiment in ground water flow model calibration, Ground Water, 36(3), 520535 .
Hopmans, J. W., J. Simunek, and K. L. Bristow (2002), Indirect estimation of soil thermal properties and water flux using heat pulse probe measurements: Geometry and dispersion effects, Water Resour. Res., 38(1), 7-1-7-13.

Johansen, O. (1975), Thermal conductivity of soils, Ph.D. dissertation, Norw. Univ. of Sci. Technol., Trondheim (CRREL draft transl. 637, 1977).

Keery, J., A. Binley, N. Crook, and J. W. N. Smith (2007), Temporal and spatial variability of groundwater-surface water fluxes: Development and application of an analytical method using temperature time series, J. Hydrol., 336(1-2), 1-16.

Kümmerer, K., and E. Helmers (2000), Hospital effluents as a source of gadolinium in the aquatic environment, Environ. Sci. Technol., 34, 573-577.

Künnemeyer, J., L. Terborg, B. Meermann, C. Brauckmann, I. Möller, and A. Scheffer (2009), Speciation analysis of gadolinium chelates in hospital effluents and wastewater treatment plant sewage by a novel HILIC/ ICP-MS method, Environ. Sci. Technol., 43, 2884-2890.

Langevin, C. D., A. M. Dausman, and M. C. Sukop (2009), Solute and heat transport model of the Henry and Hilleke laboratory experiment, Ground Water, 48(5), 757-770

Levenspiel, O., (2002), The Chemical Reactor Omnibook, Oreg. State Univ. Book Stores, Corvallis, Oreg.

Lewandowski, J., A. Putschew, D. Schwesig, C. Neumann, and M. Radke, M. (2011), Fate of organic micropollutants in the hyporheic zone of a eutrophic lowland stream: Results of a preliminary field study, Sci Total Environ., 409, 1824-1835.

Lu, S., T. Ren, Y. Gong, and R. Horton (2007), An improved model for predicting soil thermal conductivity from water content at room temperature, Soil Sci. Soc. Am. J., 71(1), 8-14.

$\mathrm{Ma}, \mathrm{R}$., and C. Zheng (2010), Effects of density and viscosity in modeling heat as a groundwater tracer, Ground Water, 48(3), 380-389.

Ma, R., C. Zheng, J. M. Zachara, and M. Tonkin (2012), Utility of bromide and heat tracers for aquifer characterization affected by highly transient flow conditions, Water Resour. Res., 48, W08523, doi:10.1029/2011WR011281.

Martínez-Santos, M., E. Ruíz-Romera, M. Martínez-López, and I. Antigüedad (2012), Influence of upwelling on the shallow water chemistry in a small wetland riparian zone, Appl. Geochem., 24(4), 854-865.

Moore, C., and D. Doherty (2005), Role of the calibration process in reducing model predictive error, Water Resour. Res., 41(5), W05020, doi: 10.1029/2004WR003501.

Neal, C., R. J. Williams, M. J. Bowes, M. C. Harrass, M. Neal, and P. Rowland (2010), Decreasing boron concentrations in UK rivers: Insights into reductions in detergent formulations since the 1990s and withincatchment storage issues, Sci. Total Environ., 408, 1374-1385.

Puckett, L. J., and W. B. Hughes (2005), Transport and fate of nitrate and pesticides: Hydrogeology and riparian zone processes, J. Environ. Qual., 34, 2278-2292.

Reddersen, K., T. Heberer, and U. Dünnbier (2002), Identification and significance of phenazone drugs and their metabolites in ground and drinking water, Chemosphere, 49, 539-544.

Scheurer, M., H.-J. Brauch, and F. T. Lange (2009), Analysis and occurrence of seven artificial sweeteners in German waste water and in soil aquifer treatment (SAT), Anal. Bioanal. Chem., 394(6), 1585-1594.

Schmidt, C., M. Bayer-Raich, and M. Schirmer (2006), Characterization of spatial heterogeneity of groundwater-stream water interactions using multiple depth streambed temperature measurements at the reach scale, Hydrol. Earth Syst. Sci., 10, 849-859.

Shook, G. M. (2001), Predicting thermal breakthrough in heterogeneous media from tracer tests, Geothermics, 30(6), 573-589.

Stonedahl, S. H., J. W. Harvey, A. Wörman, M. Salehin, and A. I. Packman (2010), A multiscale model for integrating hyporheic exchange from ripples to meanders, Water Resour. Res., 46, W12539, doi:10.1029/ 2009WR008865.

Stonestrom, D. A., and J. Constantz (2003), Heat as a tool for studying the movement of groundwater near streams, U.S. Geol. Surv. Circ. 1260, Reston, $\mathrm{Va}$.

Tangiguchi, M. (1994), Estimated recharge rates from groundwater temperatures in the Nara basin, Japan, Appl. Hydrogeol., 4, 7-13.

Ternes, T. A. (1998), Occurrence of drugs in German sewage treatment plants and rivers, Water Res., 32, 3245-3260.

Therrien, R., R. G. McLaren, E. A. Sudicky, and S. M. Panday (2010), HydroGeoSphere. A Three-dimensional Numerical Model Describing Fully-Integrated Subsurface and Surface Flow and Solute Transport, Groundwater Simul. Group, Univ. of Waterloo, Waterloo, Ont.

Thorne, D., C. D. Langevin, and M. C. Sukop (2006), Addition of simultaneous heat and solute transport and variable fluid viscosity to SEAWAT, Comput. Geosci., 32, 1758-1768. 


\section{ENGELHARDT ET AL.: ACESULFAME AS TRACER OF WASTEWATER-RELATED FLUXES}

Triska, F. J., V. C. Kennedy, R. J. Avanzino, G. W. Zellweger, and K. E. Bencala (1989), Retention and transport of nutrients in a third-order stream in northwestern California: Hyporheic processes, Ecology, 70(6), 1893-1905.

Vandenbohede, A., A. Louwyck, and L. Lebbe (2009), Conservative solute versus heat transport in porous media during push-pull tests, Transp. Porous Med., 76, 265-287.

Varni, M., and J. Carrera (1998), Simulation of groundwater age distributions, Water Resour. Res., 34(12), 3271-3281.

Verplanck, P. L., H. E. Taylor, K. D. Nordstrom, and L. Barber (2005), Aqueous stability of gadolinium in surface waters receiving sewage treatment plant effluent, Boulder Creek, Colorado, Environ. Sci. Technol., 39, 6923-6929.

Ward, D. S., M. Reeves, and L. E. Duda (1984), Verification and field comparison of the Sandia Waste-Isolation Flow and Transport (SWIFT) model, NUREG/CR-3316, SAND83-1154, Sandia Natl. Lab., Albuquerque, N. M.

Winter, T. C., J. W. Harvey, O. L. Franke, and W. M. Alley (1998), Groundwater and surface water. A single resource, U.S. Geol. Surv. Circ. 1139, Denver, Colo.

Wolf, L., C. Zwiener, and M. Zemann (2012), Tracking artificial sweeteners and pharmaceuticals introduced into urban groundwater by leaking sewer networks, Sci. Total Environ., 430, 8-19.

Zheng, C. (2010), MT3DMS v5.3. Supplemental User's Guide, Tech. Rep., Army Eng. Res. Dev. Cent., Vicksburg, Miss.

Zheng, C., and P. P. Wang (1999), MT3DMS: A modular three-dimensional multispecies model for simulation of advection, dispersion and chemical reactions of contaminants in groundwater systems-Documentation and user's guide, Contract Rep. SERDP-99-1, U.S. Army Eng. Res. Dev. Cent., Vicksburg, Miss. 